AGRICULTURE AND BIOLOGY JOURNAL OF NORTH AMERICA

ISSN Print: 2151-7517, ISSN Online: 2151-7525, doi:10.5251/abjna.2011.2.3.488.492

(C) 2011, ScienceHu $\beta$, http://www.scihub.org/ABJNA

\title{
Occurrence of organochlorine pesticide residues in groundwater and soil from Syrian coastal area
}

\author{
Hajjar M. Jamal. \\ King Faisal University, Saudi Arabia, mhajjar@kfu.edu.sa \\ Damasucus University, Syria, Email; jamalnoura@yahoo.com \\ hajjar-j@scs-net.org
}

\begin{abstract}
Soil and water samples collected biweekly over 2 month period, starting from 15 May to 30 June 2005 from Syrian costal area were analyzed to determine the occurrence of Pesticides residues and mainly the organochlorine pesticides. None of the conventional pesticides were detected neither in soil nor in water samples, the only insecticides were detected in the samples were the organoclorine insecticides. In water samples, the DDT and it is breakdown products of DDE was detected only in some sampling interval in both coastal governorates Tartous, and Latakia, and concentration typically ranged from 0.0018 to $0.0085 \mathrm{mg} / \mathrm{L}$ whereas, the ${ }_{4,4} \mathrm{DDD}$ were almost found in all water samples and ranged from 0.0076 to $0.0705 \mathrm{mg} / \mathrm{L}$. Lindane, and $\delta \mathrm{BHC}$ were detected in all samples of both governorates at concentration ranged from 0.0202 to 0.0537 and from 0.0106 to $0.136 \mathrm{mg} / \mathrm{L}$ respectively. In soil the results showed that, the high level of Lindan residues in all analyzed samples in both governorates. Concentration typically ranged from 8.54 to $22.50 \mathrm{mg} / \mathrm{kg}$, and that was due to the more recent banning of Lindan (in 2000). The residue levels of DDE were the highest among the rest of the detected $\mathrm{OC}$ residues and it ranged from 8.54 to 22.50. However the range of residues concentration of the other detected OC. Pesticides were as follow; ${ }_{4,4}$ DDD from 3.81 to $14.37,{ }_{4,4}$ DDT from 2,22 to $12.38,{ }_{2,4}$ DDT from 2.94 to 5.28 , $\mathrm{HCH}$ from 3.18 to $571,2,4 \mathrm{DDD}$ from 0.87 to 4.28 and the combination of Endosulfan and Endosulfan sulfate ranged from 0.05 to $9.18 \mathrm{mg} / \mathrm{kg}$.
\end{abstract}

Keywords: Organochlorine pesticides (OC), pesticide Residues, Gas Chromatography (GC), DDT, Lindane, Endosulfan

\section{INTRODUCTION:}

A few widely and extensively used pesticides are persistent and some are relatively non biodegradable. These pollute and stay in the elements of the environment for significant period and the questions arise as to where these pesticides will be persisted in our environment. It is clear that, the persistence, distribution and fate of pesticides are affected by many factors such as the host and the nature of the pesticides. Soil surface is the main host of the sprayed pesticides, however the surface area receiving direct and intentional application is small, but the large quantities of pesticides reach the soil surfaces were through the drift of pesticides during the application and through the atmospheric fallout (McEwen, F. et al 1979). On the other hand the use of pesticides makes it inevitable, that a portion of these will contaminate the surface water, in addition to the large amount of pesticides applied directly to water to control undesirable insects and weed. The persisted pesticides will have the chance to leach to ground water in various levels of deposit depending on the nature and chemical characteristics of the pesticides. (Marta C Akogbeto et al. 2006)

The Organochlorin pesticides in general and DDt in particular, were the most widely used insecticides in the period of $1945-1980$. They were highly efficient in controlling insect pest on crops such as cotton and other horticulture plants (Safiatou et al.2007) in addition to control the public health insects and insect disease vectors (Akogbeto et al. 2006), since those chemicals would persist in water (S.O Okeniyia et. al. 2009), and associated vegetation for several Weekes.

The intensive agricultural practices including the extent use of organo chlorine products to enhance crop yield and the wide spread of the DDT to control mosquito species and other public health insects resulted in global contamination of the organochlorin insecticides in the soil and water all over the world, 
as has been reported by the international POPs convention. In Mali, the organo chlorine insecticides were detected in the soil of cotton growing area, and $77 \%$ of the soil samples were contaminated with DDT and it is break down products in addition to Endosulfan. The later insecticide was found in the majority of soil samples, constituted $65 \%$ of the detection with the maximum concentration of $37 \mathrm{ng} /$ g. because Endosulfan insecticides was the most commonly insecticide used by farmers for controlling the cotton pest. The situation in water samples were not much better than soil, a range of insecticides were detected in water including; lindane, endosulfan`s, dieldrin and p,pDDT, p,pDE and all were below the quantification limit (Safiatou et al.2007).

A long term agricultural experiment was carried out in UK by S. N. Meijer et al. (2001), and they found that, the highest concentrations of organo chlorine insecticides in soil were with $\quad \mathrm{y}-\mathrm{HCH}$, dieldrin and ${ }_{p, p}$ DDE and they ranged from 0.1 to $10 \mathrm{ng} / \mathrm{g}$ of soil dray weight. The results observed the significant decline in the concentration of pesticides detected in the samples were taken and analyzed from the late 1960s to 1990s.

In Egypt, Dogheim et al. (1996), monitored the levels of organochlorin in soil, samples collected from Kafer El-Zayat governorate. In all soil samples, the residues of $\mathrm{HCH}$ were negligible, but DDT residues were high. Ground water samples had the highest residues of $\mathrm{HCHs}$ and DDts, followed by Nile river water and then the tap water.

The authors also extend their work and compared the presence and levels of O.C. insecticides in human milk. The milk samples were taken in, 1987 and 1990, 1996 the results reflect that, as the O.C. insecticides has been banned, and not been produced or used, most of the O.C. insecticides which has been detected before in 1986 and 1990, were not found in the samples of human milk were taken in 1996.

In Syrian situation the O.C. insecticides have been banned since 1984, and strict regulations are implemented for registration and handling of pesticides in general, but the information on the contamination of O.C. insecticides in soil and water are very rare, with an exception of investigation conducted at Damascus county side. In this study, 6 sets of soil samples were collected over a period of 11 months, from agriculture land under intensive cultivation. These samples were taken from two levels, $0-10 \mathrm{~cm}$ and from $30-45 \mathrm{~cm}$ deep. The results indicated the presence of Chlordane $(0.2-1,29)$, lindane $(0,07-0.1)$, Endrin at 0.06 but the mostly absent, Aldrin (0.03- 0.013), and DDTx of (0.13 $0.35) \mathrm{mg} / \mathrm{kg}$. The samples of ground water were collected from the studied area had, neither DDt nor Dieldrin, but lindane was detected at levels ranged between 0.042 to $0.025 \mathrm{mg} / \mathrm{L}$, (Hajjar M. J. 2000).

\section{Material and Methods:}

Study area, Sampling and Shipment: Two villages belonging to two cities located in the Syrian coast area were chosen for this study, namely ( Al Shrashir in Latakia and Al grab in Tartous). The chosen village assumed to have high pesticide usage for controlling pest and diseases on vegetable crops and citrus orchards, as well as the past usages of Arial spray in controlling the desert locust.

Soil and water samples were collected biweekly for 6 weeks period, starting from 15 May to 30 June 2005. The water samples were collected from underground wells placed in $500 \mathrm{ml}$ labeled sealed glass sealed bottles; then they were stored in chilled container and transferred directly from sampling area to the Pesticides Residues Central lab in Damascus. The soil samples were collected from several sites of surface of tilled and cultivated area $\left(1 \mathrm{~km}^{2}\right)$ surrounding the underground wells. Three samples were collected randomly from each site biweekly. The samples were collected by using 3 inches cylinder auger, each sample was separately placed in a black plastic bag labeled with the required information. The samples were stored in a chilled container and transferred directly to the Lab in Damascus.

Soil sample preparation, extraction and clean up:

At each interval of each site, one $\mathrm{Kg}$ of soil from each collected samples was kept for 3 days at room temperature to dryness.

The sample was thoroughly mixed and sifted through $2 \mathrm{~mm}$ soil sieve. Three replicates of approximately 10 $\mathrm{g}$ of sifted soil were weighed into a glass jar, and $7 \mathrm{ml}$ of $\mathrm{NH}_{4}$ was added to the sample. The mixture was manually shaken for 1 minute, and then allowed to stand for 15 minute. The soil samples were extracted with $100 \mathrm{ml}$ of mixture of hexane: acetone $(1: 1 \mathrm{~V} / \mathrm{V})$ for $12 \mathrm{hrs}$. in a shaken device. The eluate collected in saparatory funnel $(500 \mathrm{ml})$. The soil extract was then subjected to additional clean up steps. The soil eluate was washed by liquid- liquid partitioning with $200 \mathrm{ml}$ distilled water in a saparatory funnel $(500 \mathrm{ml})$. After shaking the aqueous layer was drained to other saparatory funnel, and the organic layer (hexane) was transferred to a beaker cap $(200 \mathrm{ml})$ through a filter pad of sodium sulfate (10 g). The aqueous layer 
was re-extracted with $50 \mathrm{ml}$ hexane, after the aqueous layer was discarded and the organic layer was filtered through sodium sulfate $(5 \mathrm{G})$, and combined with the other organic layer in the beaker cup, and transferred to round bottom flask and evaporated to near dryness on rotary evaporator. The side of flask was rinsed with $5 \mathrm{ml}$ hexane, the extract in the flask was quantitatively transferred to measuring cylinder of $10 \mathrm{ml}$, and then concentrated on nitrogen evaporator to $2 \mathrm{ml}$, which is the final volume in hexane prior to GC analysis.

The soil samples were air - dried before extraction. It was assumed that, the weight extract was dry weight.

Water sample extraction: Water samples were extracted using liquid- liquid extraction; each $500 \mathrm{ml}$ of water sample was poured through a filter paper in to saparatory funnel $(1 \mathrm{~L})$. The sample container was rinsed twice with $25 \mathrm{ml}$ of hexane each, and the rinsed liquid was transferred to a saparatory funnel. The mixture water $(500 \mathrm{ml})+$ hexane $(50 \mathrm{ml})$ was shaken for 20 minutes, the aqueous layer was transferred to another saparatory funnel and reextracted twice with hexane $(2 \times 50 \mathrm{ml})$, after the aqueous layer was discarded.

The organic layers were combined in the first saparatory funnel $(50 \times 3)$. Then the combined layer was filtered through granular sodium sulfate and eluted into round bottom flask, and evaporated on rotary evaporator to nearly dryness. The sides of the flask was rinsed with $5 \mathrm{ml}$ hexane, and the concentrated extract was quantitatively transferred to measuring cylinder of $10 \mathrm{ml}$, and evaporated under stream of nitrogen to $2 \mathrm{ml}$, which is the final volume in hexane prior to $\mathrm{GC}$ analysis.

Gas chromatography analysis: Soil and water extracts were analyzed using Varion 3400X Gas Chromatograph equipped with a $\mathrm{Ni}^{63}$ Micro-Electron capture detector (ECD), and Varian Star work station software. The GC was fitted with capillary column (DB-1, $30 \mathrm{~m} \times 0.25 \mu \mathrm{m} \times 0.25 \mu \mathrm{m}$ ). Helium was the carrier gas at constant column flow rate of 0.93 $\mathrm{ml} / \mathrm{min}$. The detector make up gas was nitrogen at flow rate of $60 \mathrm{ml} / \mathrm{min}$. Samples were injected in the split less mode, the injector's temperature was $250^{\circ} \mathrm{C}$, the detector temperature was $300^{\circ} \mathrm{C}$. The temperature program used for $\mathrm{DB}-1$ capillary column was $180^{\circ} \mathrm{C}$ for 2 minutes, $10^{\circ} \mathrm{C} / \mathrm{min}$. to $220^{\circ} \mathrm{C}$ held for $30 \mathrm{~min}$.

Method performance: Samples of soil previously extracted were fortified prepared and extracted using the same method and procedures as were applied for the samples. In the most cases, the recovery of pesticides ranged between 70 and 105\%, and in some cases with specific pesticides such as endosulfan, the recovery rates ranged between 55 and $58 \%$.

In case of water, deionized water was used for recovery of fortification test, and the recovery rates ranged between $75 \%$ for DDD and $110 \%$ for lindane.

\section{RESULTS}

Although the organochlorin insecticides were banned since 1984 in Syria; and many types of other conventional pesticides were used in the sampling area, none of the conventional pesticides were detected neither in soil nor in water samples, the only insecticides were detected in the samples were the organoclorine insecticides. Table (1) summarizes the residues of pesticides detected in the analyzed samples of ground water. The results showed that in Tartous, DDT detected only in sample was taken in 15 May; but in Latakia the DDT was detected at two sampling intervals, in 15 May and 30 June. However, the DDT's breakdown products of DDE was detected only in the last sampling interval in Tartous, and in the two last sampling intervals in Latakia. At concentration typically ranged from 0.0018 to 0.0085 $\mathrm{mg} / \mathrm{L}$, whereas, the ${ }_{4,4} \mathrm{DDD}$ were almost found in all sample's interval at concentration ranged from 0.0076 to $0.0705 \mathrm{mg} / \mathrm{L}$. The levels of ${ }_{4,4} \mathrm{DDD}$ residues in groundwater were much higher than the DDT and it's two later breakdown products. Lindane and $\delta$ $\mathrm{BHC}$ were detected in all samples of both governorates at concentration ranged from 0.0202 to 0.0537 and from 0.0106 to $0.136 \mathrm{mg} / \mathrm{L}$ respectively.

In soil samples, table (2) illustrates the detected residues of pesticides in the collected samples. The results showed the heavy contamination of Syrian costal area with OC insecticides and reflected the heavy uses of organochlorins insecticides and especially DDT in last decades before the banning was in act in 1984. The high level of Lindan residues in all analyzed samples in both provinces was due to the more recent banning of Lindan in 2000 and it was used mainly to control locust and hopper in the region. The residue levels of DDE and Lindane were the highest at concentration ranged from 8.54 to 22.50 and 8.28 to $28.62 \mathrm{mg} / \mathrm{kg}$ respectively, followed by ${ }_{4,4} \mathrm{DDD}$ at concentration ranged from 3.81 to $14.37,{ }_{4,4} \mathrm{DDT}$ from 2.22 to $12.38,{ }_{2,4} \mathrm{DDT}$ from 2.94 to $5.28, \mathrm{HCH}$ from 3.18 to $571,2.4 \mathrm{DDD}$ from 0.87 to 4.28 and the Residues of Endosulfan and Endosulfan sulfate combination ranged from 0.05 to $9.18 \mathrm{mg} / \mathrm{kg}$ respectively. Even though the Endosolfan has been banned since 1985 was detected in most of soil 
samples, this finding can be explained by two ways, either the Endosulfan is still illegally in use, or it has been heavily used and invested in the cultivated land for the last twenty years. Neither organophosphorous nor the other conventional or non-conventional insecticides, commonly used, were present in the water and soils in both provinces.

Table 1. Pesticide Residues in Ground water of the two coastal area (Tartous and Lattakia)

\begin{tabular}{|c|c|c|c|c|c|c|c|c|c|c|c|}
\hline $\begin{array}{l}\text { Name of } \\
\text { pesticide }\end{array}$ & $\begin{array}{l}\text { ampling } \\
\text { ervals }\end{array}$ & 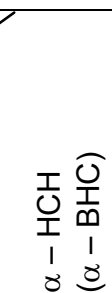 & 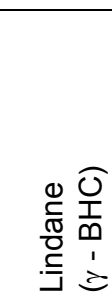 & 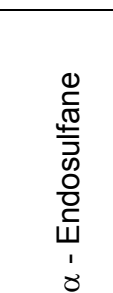 & 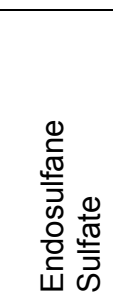 & $\frac{\text { 든 }}{\frac{0}{4}}$ & $\begin{array}{l}5 \\
0 \\
1 \\
\dot{v} \\
\dot{v}\end{array}$ & $\begin{array}{l}5 \\
0 \\
1 \\
\dot{0} \\
\dot{y}\end{array}$ & $\begin{array}{l}0 \\
\text { Oे } \\
1 \\
\dot{\Delta} \\
\dot{v}\end{array}$ & 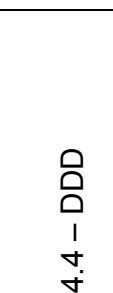 & 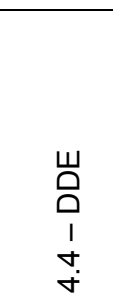 \\
\hline \multirow{4}{*}{$\begin{array}{c}\frac{0}{0} \\
\stackrel{0}{\frac{0}{0}} \\
\stackrel{5}{-}\end{array}$} & 15 May & 0.0106 & 0.0227 & n.d & n.d & n.d & 0.0047 & n.d & n.d & 0.0400 & n.d \\
\hline & 30 May & 0.0170 & 0.0202 & n.d & n.d & n.d & n.d & n.d & n.d & 0.0516 & n.d \\
\hline & 15 June & 0.0110 & 0.0241 & n.d & n.d & n.d & n.d & n.d & n.d & 0.0705 & n.d \\
\hline & 30 June & 0.0214 & 0.0307 & n.d & n.d & n.d & n.d & n.d & n.d & 0.0473 & 0.0085 \\
\hline \multirow{4}{*}{ 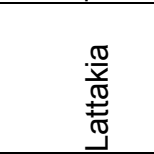 } & 15 May & 0.0134 & 0.0214 & n.d & n.d & n.d & 0.0018 & n.d & n.d & n.d & n.d \\
\hline & 30 May & 0.0269 & 0.0323 & n.d & n.d & n.d & n.d & n.d & n.d & 0.0663 & n.d \\
\hline & 15 June & 0.1360 & 0.0537 & n.d & n.d & n.d & n.d & n.d & n.d & 0.0515 & 0.0072 \\
\hline & 30 June & 0.0748 & 0.0442 & n.d & n.d & n.d & 0.0057 & n.d & n.d & 0.0076 & 0.0084 \\
\hline $\begin{array}{l}\text { Detection } \\
\text { limit } \\
(\mathrm{mg} / \mathrm{kg})\end{array}$ & DB-1 & 0.0012 & 0.0014 & 0.0027 & 0.0054 & 0.0020 & 0.0053 & 0.0042 & 0.0048 & 0.0052 & 0.0031 \\
\hline
\end{tabular}

n.d $=$ Not detected

Table 2. Pesticide Residues in soil ${ }^{\star}$ of the two coastal area (Tartous and Lattakia )

\begin{tabular}{|c|c|c|c|c|c|c|c|c|c|c|c|}
\hline \multicolumn{2}{|l|}{$\begin{array}{l}\text { Name of } \\
\text { pesticide }\end{array}$} & 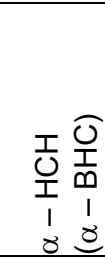 & 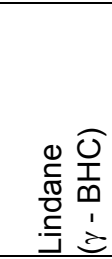 & 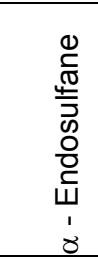 & 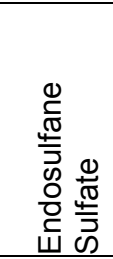 & $\frac{\frac{5}{\frac{5}{2}}}{\frac{0}{2}}$ & $\begin{array}{l}5 \\
0 \\
1 \\
\dot{N} \\
\stackrel{1}{*}\end{array}$ & $\begin{array}{l}- \\
0 \\
1 \\
\dot{8} \\
\dot{x}\end{array}$ & $\begin{array}{l}0 \\
\text { ด } \\
1 \\
\dot{v} \\
\dot{v}\end{array}$ & $\begin{array}{l}0 \\
\text { Oे } \\
1 \\
\text { ナ } \\
\dot{x}\end{array}$ & $\begin{array}{l}\text { U } \\
0 \\
1 \\
\dot{\Delta} \\
\dot{\forall}\end{array}$ \\
\hline \multirow{4}{*}{$\begin{array}{l}\frac{0}{0} \\
\frac{0}{t} \\
\frac{1}{\sigma}\end{array}$} & 15 May & 3.80 & 22.50 & 1.32 & 0.05 & n.d & 3.02 & 2.72 & 1.23 & 10.02 & 11.92 \\
\hline & 30 May & 4.02 & 18.68 & 2.14 & 6.73 & n.d & 4.44 & 3.08 & 2.06 & 14.37 & 8.28 \\
\hline & 15 June & 4.65 & 16.21 & 4.37 & 9.24 & n.d & 4.56 & 2.24 & 1.44 & 4.84 & 10.29 \\
\hline & 30 June & 3.82 & 20.47 & 2.79 & 7.22 & n.d & 2.94 & 2.22 & 0.87 & 8.55 & 14.06 \\
\hline \multirow{4}{*}{ 帝 } & 15 May & 5.71 & 18.27 & 1.07 & n.d & n.d & 5.04 & 8.94 & 3.42 & 7.25 & 28.62 \\
\hline & 30 May & 3.47 & 8.54 & 2.09 & n.d & n.d & 3.18 & 5.34 & 4.28 & 3.81 & 12.34 \\
\hline & 15 June & 3.50 & 12.06 & 4.94 & 9.18 & n.d & 5.28 & 6.97 & 3.47 & 7.70 & 14.17 \\
\hline & 30 June & 3.18 & 16.40 & n.d & 8.13 & n.d & 5.24 & 12.38 & 3.42 & 9.90 & 26.64 \\
\hline $\begin{array}{l}\text { Detection } \\
\text { limit (mg/kg) }\end{array}$ & DB-1 & 0.128 & 0.146 & 0.155 & 1.128 & 0.147 & 0.400 & 0.694 & 0.288 & 0.246 & 0.276 \\
\hline
\end{tabular}

${ }^{*}$ The mean of three analyzed samples at each interval.

n.d. Not detected

Discussion and conclusion: Numerous studies have reported the persistence of organochlorine pesticides in soil and water of cultivated land at various part of the world, such as UK (Meijer 2001), Mali (Safiatou et al. 2007), Nigeria (Okeniyia et al. 2009) and Egypt (Dogham et al. 1996, and Ahmad 
1998). This study showed occurrence of several organochlorine pesticides at low concentration in ground water and soil of Syrian coastal area, that was indicated the stop uses of old banned organochlorine insecticides such as DDT since the date of banning in 1984. However the detection of high levels of lindane in all soil samples, and at much lower concentration in groundwater indicates the more recent banning of the later chemicals. Endosulfans and Endosulfans sulphate were Imost detected in all soil samples, and were not in ground water samples. This result reflects the more recent uses of Endosulfans in agriculture. Because the DT 50 for total endosulfan, (alpha- and beta- endosulfan and endosulfan sulfate) in the field is 5-8 month, (Pesticides manual, 2006).

The presented result of DDT and its break down products in this study, are in agreement with the previously reported data on the contamination of pesticides in soil and water. DDE was the most frequent pesticides detected in water and soil samples followed by DDD and then DDT (Safiatou et al. 2007).

The significance of presence of Endosulfans, Lidane and DDT in soil and ground water in close to human and animal should be taken in to consideration.

\section{REFERENCES:}

Ahmad, M. T., M. Saad, M. Ismail and S. S. Mabrouk. (1998). Residues of some chlorinated hydrocarbon pesticides in rain water, soil and ground water, and their influence on some soil microorganisms, Journal of Environment International. 24; 665-67.
Doghem, S. M, M. El-Karka, S. A. Gad Alla, S. El-Asied, S. Y. Emel, A. M. Mohsen and S. M. Fahmy. (1996). Journal of AOAC International. 79, 1: 111-116.

Hajjar, M. J. (2001). Study of organochlorin insecticide residues in soil of Damascus Ghota. Journal of Damascus Univ. For Agric. Sci. 17:1; 80-88.

Martin, C. A., R. F. Djouaka and D. A. Kinde-gazard. (2006). Screening of pesticide residues in soil and water samples from agricultural settings, Malaria Journal, 5: 22.

McEwen, F. L. and G. R. Stephenson. (1979). The use and significance of pesticides in the environment. A WileyInterscience Publication USA. Book, 538 pp.

Meijer, S. N., C. J. Halsall, T. Harner, A. J. Peters, W. A. Ockenden, A. E. Johnston, and K. C. Jones. (2001). Organochlorine pesticide residues in Archived UK soil, Journal of Environ. Sci. Technol. 35; 1989-1995.

Okeniyia, S.O., P.A. Egwikhideb, E.E. Akporhonore and I.E. Obazed. (2009). Distribution of organochlorine and polychlorinated pesticide residues in water bodies of some rivers in northern Nigria, EJEAFChe, 8 (11); 1269-1274.

Safiatou, B. D., J. M. Cobb, and Donald E. M. (2007). pesticide residues in soil and water from four cotton growing area of Mali, West Africa, Journal of Agriculture, Food and Environment Sciences, 1; 1-9.

Mann, P. J., (2006). Pesticides manual, BCPC 